\title{
A drenagem do solo no perfilhamento não estimula o desenvolvimento do sistema radicular do arroz irrigado cultivado no sistema pré-germinado
}

\author{
Soil drainage at tillering does not stimulate pre-germinated rice root growth
}

\author{
Luís Sangoi ${ }^{\mathrm{I}}$ Paula Bianchet ${ }^{\mathrm{II}}$ Paulo Roberto Ernani ${ }^{\mathrm{III}}$ Paulo Regis Ferreira da Silva ${ }^{\mathrm{IV}}$ \\ Ciro Franco Fiorentin ${ }^{V}$ Claitson Gustavo Zanin ${ }^{\text {II }}$ Amauri Schmitt ${ }^{\text {II }}$ \\ Dario Antunes de Oliveira Netov ${ }^{\mathrm{V}}$ Franchielli Motter $^{\mathrm{V}}$ \\ Cleber SchweitzerIV
}

RESUMO

Embora não seja oficialmente recomendada pelas entidades de pesquisa, a retirada da água no perfilhamento é uma prática cultural frequentemente utilizada pelos produtores de arroz irrigado no Estado de Santa Catarina, visando a estimular a emissão de raízes e a reduzir o acamamento. Este trabalho foi conduzido objetivando-se avaliar as alterações nas características morfológicas de raízes e da parte aérea do arroz promovidas pela drenagem no perfilhamento. O experimento foi conduzido em casa de vegetação, no município de Lages, SC. Foram testados quatro sistemas de manejo da irrigação durante o perfilhamento: irrigação contínua, retirada da água 45 dias após a semeadura, com retorno da irrigação aos 7, 14 e 21 dias após a drenagem. Para cada sistema de manejo da irrigação, avaliaram-se duas cultivares: "EPAGRI106" (precoce) e "EPAGRI-109" (tardia). As unidades experimentais foram baldes com $7 \mathrm{~kg}$ de solo e o delineamento experimental foi completamente casualizado. O ensaio foi implantado em 24/09/2004, utilizando-se sementes prégerminadas. Os parâmetros de parte área foram determinados 22 dias após o início da drenagem, quando todas as unidades experimentais estavam novamente inundadas. Os parâmetros radiculares foram determinados logo após a coleta da parte aérea. O comprimento, a área, o volume radicular e a matéria seca de raízes reduziram-se com o aumento na duração do período de drenagem nas duas cultivares. A retirada da água no afilhamento não afetou a produção de fitomassa na parte aérea, mas reduziu a relação raiz/parte área. O número de folhas senescidas foi maior e a estatura da planta foi menor no tratamento com maior período de drenagem do que naquele onde a irrigação foi contínua. A drenagem no afilhamento não demonstrou ser uma prática cultural efetiva para estimular o desenvolvimento radicular do arroz irrigado cultivado no sistema pré-germinado.

Palavras-chave: Oryza sativa, afilhamento, cultivar, irrigação, raízes.

\begin{abstract}
Even though it is not officially recommended by the research institutes, water removal at tillering is a management practice frequently used by pre-germinated rice growers in the State of Santa Catarina, aiming to stimulate root growth and to reduce plant lodging. A green-house study was carried out with the objective of evaluate the changes in root and shoot morphological traits promoted by soil drainage at tillering. The experiment was performed in the city of Lages, $S C$, Brazil. Four water management systems were tested: continuous flooding, water removal at tillering and re-flooding at 7,14 and 21 days after soil drainage. Two cultivars were evaluated for each irrigation system: 'Epagri 106' (short season) and 'Epagri 109' (long season). The experimental units were $7 \mathrm{~kg}$ pots disposed in a completely randomized experimental design. The experiment was installed on 09/24/2004, using pre-germinated seeds. The shoot parameters were determined 22 days after soil drainage, when all experimental units were re-flooded. The root parameters were determined after shoot harvesting. The root length, area, volume and dry matter were reduced with the increase in soil drainage period for both cultivars. The water withdraw at tillering did not affect shoot dry matter but it decreased the root/shoot ratio. The number of senesced leaves was higher and plant height was lower in the treatments with the longer drainage period than when the irrigation was continuous. Soil drainage at tillering does not seem to be an effective management practice to enhance root development in the pre-germinated rice production system.
\end{abstract}

Key words: Oryza sativa, cultivars, irrigation, roots, tillering.

\section{INTRODUÇÃO}

O arroz é uma das principais culturas anuais produzidas no Brasil, correspondendo a 15-20\% do total

\footnotetext{
IDepartamento de Fitotecnia, Universidade do Estado de Santa Catarina (UDESC), CP. 281, 88520-000, Lages, SC, Brasil. Email:a2ls@cav.udesc.br. Autor para correspondência.

IIPrograma de Pós-graduação em Agronomia, UDESC, Lages, SC, Brasil.

IIIDepartamento de Solos, UDESC, Lages, SC, Brasil.

${ }^{\text {IV }}$ Departamento de Plantas de Lavoura, Universidade Federal do Rio Grande do Sul (UFRGS), Porto Alegre, RS, Brasil.

${ }^{v}$ Curso de Agronomia, UDESC, Lages, SC, Brasil.
} 
de grãos colhidos no país (EMBRAPA, 2004). No Estado de Santa Catarina, o arroz é cultivado por aproximadamente 6.000 famílias, numa área de 150.000ha, com uma produção anual que supera milhão de toneladas (ICEPA, 2005).

Os produtores de arroz irrigado do Estado de Santa Catarina utilizam o sistema de cultivo prégerminado, no qual o preparo do solo e a semeadura ocorrem com o solo inundado, utilizando-se sementes em fase adiantada de germinação. O sistema prégerminado propicia algumas vantagens, como o aumento na disponibilidade de nutrientes, redução na incidência de plantas daninhas não-aquáticas, decréscimo na ocorrência de brusone e de bicheira da raiz. Estes benefícios favorecem a obtenção de produtividades elevadas no Estado, superiores a $7.000 \mathrm{~kg} \mathrm{ha}^{-1}$ (EPAGRI, 2003).

O manejo da irrigação é fundamental para que as vantagens do sistema pré-germinado sejam otimizadas. Neste sentido, recomenda-se que a irrigação seja contínua, iniciando-se a colocação de água nos quadros durante o preparo do solo e retirando-a no final do período de enchimento de grãos (EPAGRI, 2002).

Por outro lado, a drenagem do solo na fase de perfilhamento da cultura é uma prática de manejo comumente utilizada em Santa Catarina, principalmente na região do Alto Vale do Itajaí (BIANCHET, 2006). Os produtores a realizam porque lhe atribuem efeitos benéficos sobre características relacionadas à planta e ao solo.

Em relação às características de planta, um fator importante a ser considerado é a ocorrência de acamamento. Os produtores afirmam que a drenagem no perfilhamento proporciona maior enraizamento, o que evita o acamamento (SANGOI et al., 2005). Porém, CARMONA et al. (2001) verificaram reduções na produção de matéria seca da parte aérea e no volume de raízes à medida que aumentou a duração do período de retirada da água, a partir do décimo dia após a semeadura. Desta forma, é possível que a redução do acamamento seja devida ao decréscimo no crescimento da parte aérea e não ao maior enraizamento da planta.

A retirada da água da lavoura pode causar problemas de déficit hídrico à cultura, se o período de drenagem for prolongado e não ocorrer precipitação pluvial durante esta etapa. $\mathrm{O}$ arroz necessita de água durante todo o seu ciclo, sendo que a falta de água no perfilhamento pode reduzir o número de perfilhos efetivos, diminuindo o número de panículas por área e comprometendo a produtividade da cultura (RAMIREZ, 2005).

Em relação às características físicas do solo, os produtores alegam que a drenagem no perfilhamento melhora a sustentação física do solo às colheitadeiras (BIANCHET et al., 2005). Contudo, EBERHARDT et al. (2001) avaliaram a resistência do solo à penetração no momento da colheita, nos tratamentos com inundação contínua e drenagem por 23 e 34 dias durante o perfilhamento, e não constataram diferenças na sustentação física do solo.

Há poucas informações sobre os efeitos da retirada de água no perfilhamento nos parâmetros radiculares e de parte aérea do arroz irrigado. Em vista disto, conduziu-se este trabalho com o objetivo de avaliar o efeito de diferentes períodos de drenagem durante o perfilhamento sobre as características morfológicas do sistema radicular e da parte aérea de duas cultivares de arroz irrigado cultivadas no sistema pré-germinado.

\section{MATERIAL E MÉTODOS}

O experimento foi conduzido em casa de vegetação, no município de Lages, SC. As unidades experimentais foram constituídas por baldes plásticos, contando com $7 \mathrm{~kg}$ de solo peneirado, sendo o solo classificado como CAMBISSOLO Háplico distrófico (EMBRAPA, 1999). O solo apresentava as seguintes características químicas antes da implantação do ensaio: pH SMP=4,74; $\mathrm{P}=32,5 \mathrm{mg} \mathrm{dm}^{-3} ; \mathrm{K}=126,5 \mathrm{mg} \mathrm{dm}^{-3}$; $\mathrm{Ca}=8,3 \mathrm{cmol}_{\mathrm{c}} \mathrm{dm}^{-3} ; \mathrm{Mg}=0,8 \mathrm{cmol}_{\mathrm{c}} \mathrm{dm}^{-3}$ e matéria orgânica $20 \mathrm{~g} \mathrm{~kg}^{-1}$.

Testaram-se quatro períodos de drenagem do arroz irrigado na fase do perfilhamento:T1 = sem drenagem da água; $\mathrm{T} 2$ = drenagem aos 45 dias após a semeadura (estádio V6 da escala proposta por COUNCE et al., 2000) e retorno da irrigação sete dias após a drenagem; T3 = drenagem aos 45 dias após a semeadura e retorno da irrigação 14 dias após a drenagem; $\mathrm{T} 4$ = drenagem aos 45 dias após a semeadura e retorno da irrigação 21 dias após a drenagem. Para cada período de drenagem, utilizaram-se duas cultivares: "Epagri 106”, de ciclo precoce ( < 120 dias), e “Epagri 109”, de ciclo tardio ( $>135$ dias). O delineamento experimental foi inteiramente casualizado com três repetições por tratamento.

O solo foi inundado um mês antes da semeadura, simulando o que é feito a campo, onde a água é colocada nos quadros durante o preparo de solo. A adubação utilizada seguiu a necessidade definida pela análise de solo. Aplicaram-se quantidades equivalentes a 20kg de $\mathrm{P}_{2} \mathrm{O}_{5}$ ha $^{-1}, 40 \mathrm{~kg} \mathrm{~K}_{2} \mathrm{O} \mathrm{ha}^{-1}$ e $100 \mathrm{~kg}$ $\mathrm{N} \mathrm{ha}^{-1}$, as quais foram corrigidas para os $7 \mathrm{~kg}$ de solo em cada unidade experimental. O fósforo e o potássio foram incorporados ao solo dois dias antes da semeadura. A adubação nitrogenada foi feita em

Ciência Rural, v.38, n.1, jan-fev, 2008. 
cobertura quando as plantas estavam no estádio V4 da escala proposta por COUNCE et al. (2000).

A pré-germinação foi feita seguindo metodologia descrita pela EPAGRI (2002). A semeadura foi feita manualmente, no dia 24/09/2004, com auxílio de uma pinça, utilizando-se 10 sementes pré-germinadas por unidade experimental. Após a emergência da cultura, uniformizou-se o estande para nove plantas por vaso, o que equivaleu à densidade de $250 \mathrm{pl} \mathrm{m}^{-2}$. A temperatura durante o dia dentro da casa de vegetação foi controlada com auxílio de ventiladores para que não ultrapasse $30^{\circ} \mathrm{C}$ durante o período de desenvolvimento da cultura.

Ao final do período mais longo de drenagem (66 dias após a semeadura) procederam-se às seguintes avaliações na parte aérea: estatura, número de perfilhos por planta, estádio fenológico da cultura, de acordo com a escala proposta por COUNCE et al. (2000), número de folhas totais, verdes e senescidas.

Depois de concluídas as avaliações morfológicas, as plantas foram colhidas, separando-se as raízes da parte aérea. A massa de raízes úmidas foi obtida depois de deixá-las durante dois minutos entre camadas de papel toalha. Após isso, retirou-se uma subamostra de $0,2 \mathrm{~g}$ de raiz para posterior determinação do comprimento. As partes das plantas foram secadas em estufa a $60^{\circ} \mathrm{C}$ até atingirem massa constante. Em seguida, efetuou-se a pesagem para determinação da matéria seca de raiz e de parte aérea e relação da matéria seca de raiz/parte aérea.

Os parâmetros morfológicos da raiz foram determinados conforme metodologia apresentada por SCHENK \& BARBER (1979). O comprimento (L) foi determinado pelo método de intersecção descrito por TENNANT (1975). O raio médio (R) foi calculado pela fórmula $\mathrm{R}=\left(\mathrm{P}_{\mathrm{f}} / \mathrm{L} \pi\right)^{1 / 2}$, em que Pf é o peso fresco da raiz. Essa fórmula pressupõe a forma cilíndrica de raízes com densidade de $1,0 \mathrm{~g} \mathrm{~cm}^{-3}$. A área foi calculada segundo ROSSIELLO et al. (1995) pela fórmula $A=(2 \pi R L)$ e o volume através da expressão $V=\left(\pi R^{2}\right) L$.

Os dados obtidos foram submetidos à análise de variância (teste F). Quando alcançada significância estatística, as médias foram comparadas pelo teste de Duncan, em nível de 5\% de probabilidade de erro $(\mathrm{P}<0,05)$, e através de análise de regressão polinomial.

\section{RESULTADOS E DISCUSSÃO}

O comprimento, a área e o volume radicular do arroz irrigado foram afetados pelos sistemas de manejo da água. Houve diferenças significativas entre cultivares apenas para os valores de volume de raiz.
Estes três parâmetros radiculares reduziram-se quadraticamente com aumento no período de drenagem do solo (Figura 1). Resultados semelhantes foram encontrados por DAS \& JAT (1977), com o comprimento radicular sendo maior no tratamento sem interrupção da irrigação do que nos tratamentos com inundação alternada e sequeiro.

A redução nos parâmetros radiculares supracitados provavelmente ocorreu pela necessidade de troca de raízes nos tratamentos com retirada da água para se adaptarem ao ambiente aeróbico, promovida pela oxigenação do solo. O comportamento destes três parâmetros radiculares indica que a drenagem da água no perfilhamento pode contribuir para aumentar o acamamento, em função da redução do comprimento, da área e do volume radicular, que podem proporcionar menor sustentação das plantas de arroz.

Além disso, a redução no desenvolvimento radicular ocasionada pelo aumento do período de drenagem proporciona menor exploração do solo pelas raízes. Raízes mais longas e finas são mais eficientes na absorção de nutrientes no solo, pois desenvolvem maior superfície de absorção por unidade de volume de raiz e exploram maior volume de solo, devido à característica de fluxo radial dos nutrientes ao redor da raiz(HORN, 2004).

A cultivar “Epagri 106” apresentou maior volume radicular do que a "Epagri 109" (Figura 1c). Isso provavelmente ocorreu pela característica de precocidade da "Epagri 106”, que promove rápido estabelecimento do sistema radicular. LOPES et al. (1994) verificaram que o crescimento inicial de raízes de arroz é lento, aumentando na fase de perfilhamento e tornando a se reduzir no período de desenvolvimento da panícula. Para cultivares mais precoces, o período de maior desenvolvimento de raízes é menor e mais rápido pelo período curto de perfilhamento.

A matéria seca de raízes diferiu entre sistemas de manejo da irrigação e cultivares (Tabela 1). Quanto maior o período de drenagem, menor a quantidade de massa alocada às raízes. Esse comportamento pode ser explicado pela redução no comprimento, na área e no volume de raízes promovida pela retirada da água (Figura 1). As raízes aumentam seu crescimento com o perfilhamento. Desta forma, qualquer ação que paralise o crescimento radicular nesta fase reduzirá a matéria seca de raízes durante todo o ciclo da cultura. A cultivar "Epagri 106” apresentou maior matéria seca de raízes que a “Epagri 109”. Devido a sua precocidade, ela apresenta menor período de perfilhamento. Assim, no momento das coletas, as plantas provavelmente estavam no pico de crescimento radicular. O ciclo curto da cultivar “Epagri 106” também 


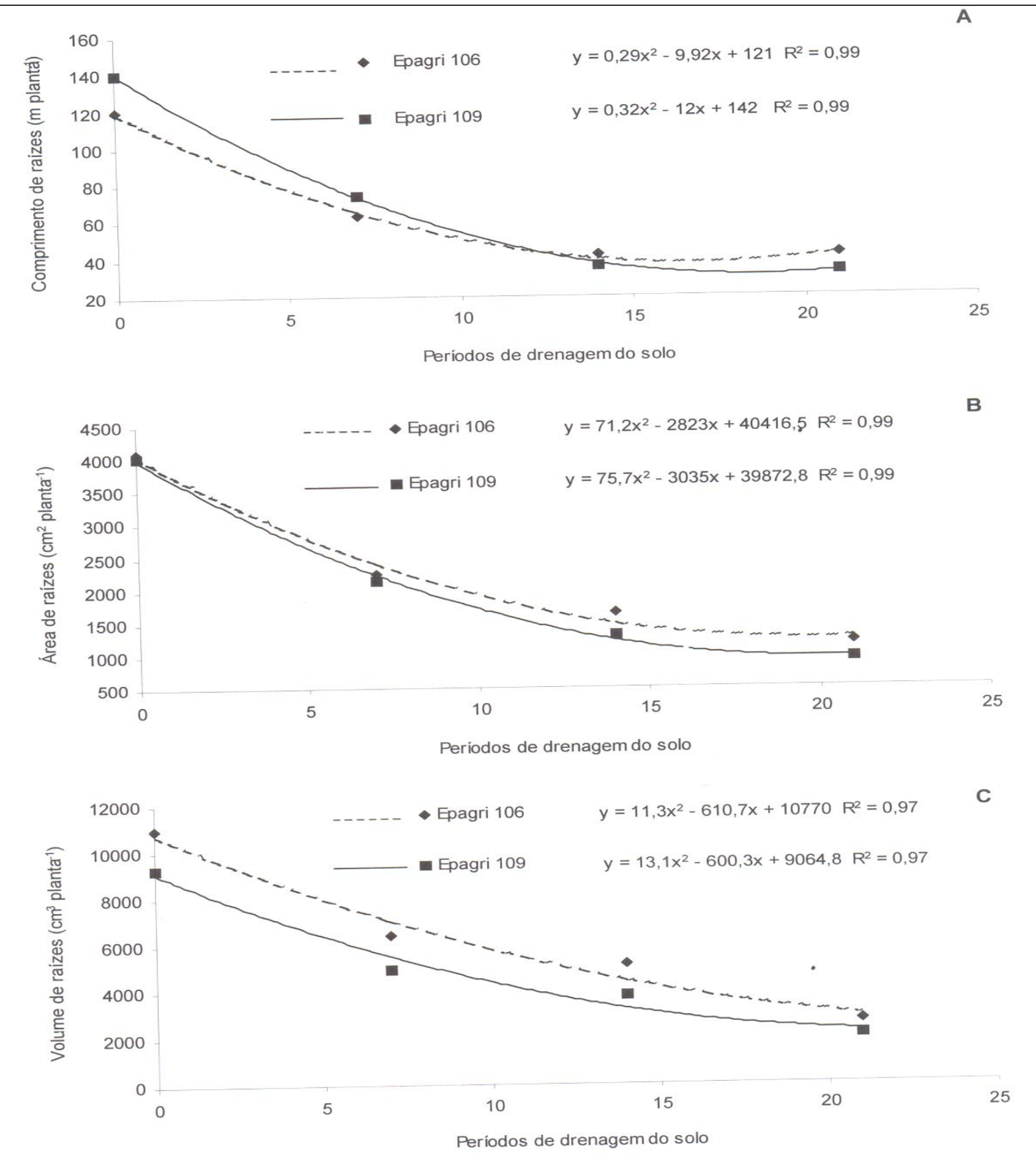

Figura 1 - Comprimento de raízes (A), área de raízes (B) e volume de raízes (C) de duas cultivares de arroz (“Epagri 106” e “Epagri 109”) submetidas a diferentes sistemas de manejo da irrigação em casa de vegetação. Lages, SC, 2004.

contribuiu para que ela apresentasse maiores produções de matéria seca de parte aérea e total do que a "Epagri 109”.

O sistema de manejo da irrigação não afetou significativamente a produção de fitomassa de parte aérea. Por outro lado, quanto maior o período de drenagem, menor foi a relação raiz/parte aérea. Este comportamento da relação raiz/parte aérea também foi observado por CARMONA et al. (2001) e contraria a afirmação feita por alguns agricultores do Alto Vale do Itajaí de que um dos benefícios da retirada da água no perfilhamento é a maior produção de raízes pela planta, a qual se reflete em maior sustentabilidade da lavoura na colheita e menor suscetibilidade ao acamamento.

O número de folhas verdes na colheita foi menor quando as unidades experimentais

Ciência Rural, v.38, n.1, jan-fev, 2008. 
A drenagem do solo no perfilhamento não estimula o desenvolvimento do sistema radicular do arroz...

Tabela 1 - Matéria seca de parte aérea, matéria seca de raiz, matéria seca total e relação raiz/parte aérea de duas cultivares de arroz, submetidas a diferentes sistemas de manejo da irrigação em casa de vegetação. Lages, SC, 2004.

\begin{tabular}{|c|c|c|c|c|c|c|}
\hline \multirow{2}{*}{$\begin{array}{l}\text { Períodos de drenagem após } \\
\mathrm{V}^{1 /}{ }^{\text {(dias) }}\end{array}$} & Epagri 106 & Epagri 109 & Média & Epagri 106 & Epagri 109 & Média \\
\hline & \multicolumn{2}{|c|}{ Matéria seca de parte aérea (g planta ${ }^{-1}$ ) } & \multicolumn{4}{|c|}{ Matéria seca de raiz (g planta ${ }^{-1}$ ) } \\
\hline 0 & 2,0 & 1,8 & $1,9 \mathrm{~ns}^{2 /}$ & 1,5 & 1,0 & $1,2 \mathrm{a}$ \\
\hline 7 & 2,1 & 1,8 & 1,9 & 0,8 & 0,7 & $0,7 \mathrm{~b}$ \\
\hline 14 & 2,0 & 1,7 & 1,8 & 0,5 & 0,5 & $0,5 \mathrm{c}$ \\
\hline 21 & 2,0 & 1,7 & 1,8 & 0,3 & 0,3 & $0,3 \mathrm{~d}$ \\
\hline \multirow[t]{2}{*}{ Média } & $2,0 \mathrm{~A}^{3 /}$ & $1,7 \mathrm{~B}$ & C V - 6,2\% & $0,8 \mathrm{~A}$ & $0,6 \mathrm{~B}$ & C V $-8,6 \%$ \\
\hline & \multicolumn{2}{|c|}{$\begin{array}{c}\text { Matéria seca total } \\
\left({\left.\text { ( } \text { planta }^{-1}\right)}^{\text {la }}\right.\end{array}$} & \multicolumn{4}{|c|}{ Relação raiz/parte aérea } \\
\hline 0 & 3,5 & 2,8 & $3,1^{\mathrm{a}}$ & 0,727 & 0,563 & 0,645 a \\
\hline 7 & 2,9 & 2,5 & $2,7 b$ & 0,385 & 0,369 & $0,377 \mathrm{~b}$ \\
\hline 14 & 2,5 & 2,1 & $2,3 \mathrm{c}$ & 0,262 & 0,270 & $0,266 \mathrm{c}$ \\
\hline 21 & 2,3 & 2,0 & $2,2 \mathrm{c}$ & 0,156 & 0,152 & $0,154 \mathrm{~d}$ \\
\hline Média & $2,8 \mathrm{~A}$ & $2,3 \mathrm{~B}$ & C V $-9,3 \%$ & $0,382 \mathrm{~A}$ & 0,338 B & C V $-9,8 \%$ \\
\hline
\end{tabular}

${ }^{1 /}$ De acordo com escala proposta por COUNCE et al. (2000).

${ }^{2 /} \mathrm{ns}=$ Diferenças não significativas pelo teste $\mathrm{F}(\mathrm{P}<0,05)$.

${ }^{3 /}$ Médias seguidas pela mesma letra maiúscula na linha ou minúscula na coluna não diferem estatisticamente pelo Teste de Duncan (P<0,05).

permaneceram por 21 dias sem água do que nos outros tratamentos (Tabela 2). Isto demonstra que a drenagem só afetou este parâmetro quando o período foi prolongado. Não houve diferenças entre cultivares quanto ao número de folhas verdes.

O número de folhas senescidas foi afetado significativamente pela duração do período de drenagem e pela cultivar. A drenagem por 21 dias aumentou a senescência foliar em relação aos demais tratamentos. Isso pode ter sido ocasionado pelo agravamento da deficiência hídrica neste tratamento e pela menor absorção de nitrogênio $(\mathrm{N})$ pela planta, devido à falta de água que é importante para a chegada do $\mathrm{N}$ até a superfície radicular por fluxo de massa (HORN et al., 2006). O número de folhas senescidas foi maior na cultivar “Epagri 109” do que na “Epagri 106”. Isto pode estar relacionado com o maior número de folhas totais e a maior produção de afilhos da cultivar de ciclo tardio (Tabela 3), características que apressam a senescência das folhas mais velhas na planta.

A supressão da irrigação por sete e 21 dias reduziu a estatura de planta, em relação ao tratamento em que a lâmina de água foi mantida permanentemente, na média das duas cultivares (Tabela 2). Este resultado

Tabela 2 - Folhas verdes e senescidas, estatura de planta e estádio de desenvolvimento de duas cultivares de arroz submetidas a diferentes sistemas de manejo da irrigação em casa de vegetação. Lages, SC, 2004.

\begin{tabular}{|c|c|c|c|c|c|c|}
\hline \multirow{2}{*}{$\begin{array}{l}\text { Períodos de drenagem } \\
\text { após } \mathrm{V}^{1 /} \text { (dias) }\end{array}$} & Epagri 106 & Epagri 109 & \multirow{2}{*}{ Média } & Epagri 106 & Epagri 109 & \multirow{2}{*}{ Média } \\
\hline & \multicolumn{2}{|c|}{ Folhas verdes $\left(n^{0}\right.$ planta $\left.^{-1}\right)$} & & \multicolumn{2}{|c|}{ Folhas senescidas $\left(n^{0}\right.$ planta $\left.^{-1}\right)$} & \\
\hline 0 & 18,5 & 21,7 & $20,1 \mathrm{a}^{3 /}$ & 8,5 & 9,8 & $9,1 \mathrm{~b}$ \\
\hline 7 & 21,6 & 18,7 & $20,2 \mathrm{a}$ & 7,7 & 10 & $8,9 \mathrm{~b}$ \\
\hline 14 & 19,3 & 19,5 & $19,4 \mathrm{a}$ & 8,4 & 10,1 & $9,2 \mathrm{~b}$ \\
\hline 21 & 16,7 & 17,2 & $17,0 \mathrm{~b}$ & 10,7 & 12,5 & $11,6 \mathrm{a}$ \\
\hline \multirow[t]{2}{*}{ Média } & $19,0 \mathrm{~ns}^{2 /}$ & 19,2 & C V $-5,7 \%$ & 8,8 B & $10,6 \mathrm{~A}$ & $\mathrm{C} \mathrm{V}-6,2 \%$ \\
\hline & \multicolumn{2}{|c|}{ Estatura de planta (cm) } & & \multicolumn{2}{|c|}{ Estádio de desenvolvimento $^{1 /}$} & \\
\hline 0 & 43,8 & 38,0 & $40,8 \mathrm{a}$ & 8,8ns & 9,8 & $9,3 \mathrm{~ns}$ \\
\hline 7 & 39,4 & 36,4 & $37,9 \mathrm{~b}$ & 9,4 & 9,2 & 9,3 \\
\hline 14 & 41,2 & 36,2 & $38,7 \mathrm{ab}$ & 9,1 & 8,7 & 8,9 \\
\hline 21 & 38,3 & 36,2 & $37,3 \mathrm{~b}$ & 8,9 & 9,2 & 9,1 \\
\hline Média & $40,7 \mathrm{~A}$ & $36,7 \mathrm{~B}$ & $\mathrm{C} \mathrm{V}-3,7 \%$ & $9,1 \mathrm{~ns}$ & 9,2 & C V $-4,3 \%$ \\
\hline
\end{tabular}

\footnotetext{
${ }^{1 /}$ De acordo com escala proposta por COUNCE et al. (2000).

${ }^{2 /} \mathrm{ns}=$ Diferenças não-significativas pelo teste $\mathrm{F}(\mathrm{P}<0,05)$.

${ }^{3 /}$ Médias seguidas pela mesma letra maiúscula na linha ou minúscula na coluna não diferem estatisticamente pelo Teste de Duncan (P<0,05).
} 
Tabela 3 - Folhas totais e produção de perfilhos de duas cultivares de arroz submetidas a diferentes sistemas de manejo da irrigação em casa de vegetação. Lages, SC, 2004.

\begin{tabular}{|c|c|c|c|c|}
\hline \multirow{2}{*}{$\begin{array}{l}\text { Períodos de drenagem após } \\
\mathrm{V6}^{1 /} \text { (dias) }\end{array}$} & Epagri 106 & Epagri 109 & Epagri 106 & Epagri 109 \\
\hline & \multicolumn{2}{|c|}{ Folhas totais $\left(n^{0} \text { planta }^{-1}\right)^{2 /}$} & \multicolumn{2}{|c|}{ Perfilhos $\left(n^{0} \text { planta }^{-1}\right)^{3 /}$} \\
\hline 0 & 26,9 & $31,5 \mathrm{~ns}^{4 /}$ & 6,9 & $7,3 \mathrm{~ns}$ \\
\hline 7 & 29,3 & 28,7 & 7,1 & 6,7 \\
\hline 14 & 27,7 & 29,5 & 6,1 & 7,5 \\
\hline 21 & 27,4 & 29,7 & 5,8 & 7,5 \\
\hline Média & $27,9 \mathrm{~B}^{5 /}$ & 29,9 A & $6,5 \mathrm{~B}$ & 7,3 A \\
\hline
\end{tabular}

${ }^{1 /}$ De acordo com escala proposta por COUNCE et al. (2000).

${ }^{2 /} \mathrm{C}$ V $-5,4 \%$.

${ }^{3 /} \mathrm{C}$ V $-7,4 \%$.

${ }^{4 /}$ ns = Diferenças não-significativas pelo teste $\mathrm{F}(\mathrm{P}<0,05)$.

${ }^{5 /}$ Médias seguidas pela mesma letra maiúscula na linha ou minúscula na coluna não diferem estatisticamente pelo Teste de Duncan (P<0,05).

pode ser indicativo de que a menor percentagem de plantas acamadas, mencionada pelos produtores como justificativa para proceder À drenagem no perfilhamento, deve-se mais à redução na estatura de planta do que ao maior desenvolvimento das suas raízes. As plantas da cultivar "Epagri 106” apresentaram maior estatura do que as da cultivar "Epagri 109” no dia da colheita. Não houve efeito significativo do sistema de manejo da água e da cultivar sobre a estádio de desenvolvimento da cultura 66 dias após a semeadura.

O número de folhas totais e o número de perfilhos produzidos pelas cultivares não foram afetados pelo sistema de manejo da água. A cultivar “Epagri 109” produziu mais perfilhos do que a "Epagri 106”, na média dos quatro sistemas de manejo da água (Tabela 3), o que se deve à característica de ciclo tardio com maior período de perfilhamento.

\section{CONCLUSÕES}

A retirada de água no perfilhamento promoveu prejuízos ao desenvolvimento do sistema radicular, apressou a senescência foliar, reduziu o número de folhas verdes e a estatura de planta do arroz irrigado cultivado no sistema pré-germinado.

\section{AGRADECIMENTOS}

Ao Conselho Nacional de Desenvolvimento Científico e Tecnológico (CNPq), pela concessão das bolsas de produtividade em pesquisa aos professores e de iniciação científica aos acadêmicos de graduação envolvidos no trabalho.

À Coordenação de Aperfeiçoamento de Pessoal de Nível Superior (CAPES), pela concessão das bolsas aos acadêmicos do Curso de Mestrado em Produção Vegetal da UDESC que participaram do trabalho.

\section{REFERÊNCIAS}

BIANCHET, P. Períodos de drenagem do solo no perfilhamento em arroz irrigado cultivado nos sistema pré-germinado. 2006. 90f. Dissertação (Mestrado em Produção Vegetal) - Curso de Pós-graduação em Agronomia, Universidade do Estado de Santa Catarina.

BIANCHET, P. et al. Períodos de supressão da irrigação durante o perfilhamento e rendimento de grãos do arroz no sistema prégerminado. In: CONGRESSO BRASILEIRO DE ARROZ IRRIGADO, 4., 2005, Santa Maria, RS. Resumos Expandidos... Santa Maria: Orium, 2005. V.1. 530p. p.331-333.

CARMONA, R. et al. Crescimento da planta de arroz irrigado afetado pela duração do período de retirada da lâmina de água. In: CONGRESSO BRASILEIRO DE ARROZ IRRIGADO, 2., 2001, Porto Alegre, RS. Anais... Porto Alegre: IRGA, 2001. 550p. p.235-237.

COUNCE, P.A. et al. A uniform, objective, and adaptive system for expressing rice development. Crop Science, Madison, v.40, n.2, p.436-443, 2000.

DAS, D.K.; JAT, R.L. Influence of three soil-water regimes on root porosity and growth of four rice varieties. Agronomy Journal, Madison, v.69, n.2, p.197-200, 1977.

EBERHARDT, D.S. et al. Manejo da irrigação no período de perfilhamento do arroz irrigado. In: CONGRESSO BRASILEIRO DE ARROZ IRRIGADO, 2., 2001, Porto Alegre, RS. Anais... Porto Alegre: IRGA, 2001. 570p. p.178-180.

EMBRAPA. Centro Nacional de Pesquisa de Solos. Sistema brasileiro de classificação de solos. Brasília: EMBRAPA, 1999. 412p.

EMBRAPA. Arroz Irrigado no Sul do Brasil. Brasília: Embrapa, 2004. 680p.

EPAGRI. A cultura do arroz irrigado pré-germinado. Florianópolis: EPAGRI, 2002. 273p.

EPAGRI. Algumas recomendações para a produção de arroz irrigado com baixo impacto ambiental. Florianópolis: EPAGRI, 2003. 52p. (Boletim Didádico, 52). 
HORN, D. Atributos morfo-fisiológicos da absorção de nutrientes em genótipos de milho e seus desempenhos agronômico e econômico em função de níveis de manejo. 2004. 111f. Dissertação (Mestrado em Ciência do Solo) Curso de Pós-graduação em Agronomia, Universidade do Estado de Santa Catarina.

HORN, D. et al. Parâmetros cinéticos e morfológicos da absorção de nutrientes em cultivares de milho com variabilidade genética contrastante. Revista Brasileira de Ciência do Solo, Viçosa, v.30, n.1, p.77-85, 2006.

ICEPA. Instituto de Planejamento e Economia Agrícola de Santa Catarina. Produção de Arroz em Santa Catarina na safra de 2004/2005. Capturado em 20 ago. 2005. Online. Disponível na Internet http//www.icepa.com.br.

LOPES, S.I.G. et al. Desenvolvimento do sistema radicular do arroz irrigado. Revista Brasileira de Ciência do Solo Campinas, v.18, n.2, p.273-278, 1994

RAMIREZ, H.V. et al. Enchimento de grãos de arroz irrigado em função do manejo da água para a colheita. In: CONGRESSO BRASILEIRO DE ARROZ IRRIGADO, 4., 2005, Santa Maria,
RS. Resumos Expandidos... Santa Maria: Orium, 2005. V.1. 530p. p.354-356

ROSSIELLO, R.O. P. et al. Comparação dos métodos fotoelétrico e da intersecção na determinação de área, comprimento e raio médio radicular. Pesquisa Agropecuária Brasileira, Brasília. v.30, n.5, p.633-638, 1995.

SANGOI, L. et al. Efeito de diferentes períodos de supressão da irrigação no perfilhamento sobre o desenvolvimento radicular e da parte aérea do arroz pré-germinado. In: CONGRESSO BRASILEIRO DE ARROZ IRRIGADO, 4., 2005, Santa Maria, RS. Resumos Expandidos... Santa Maria: Orium, 2005. V.1. 530p. p.294-295.

SCHENK, M.K.; BARBER, S.A. Phosphate uptake by corn as affected by soil characteristics and root morphology. Soil Science Society of America Journal, Madison, v.43, n.4, p.880-883, 1979.

TENNANT, D. A test of a modified line intercept method of estimating root length. Journal of Ecology Applied, Londres, v.63. n.4, p.995-1001, 1975. 